http://dx.doi.org/10.7197/1305-0028.71278

\title{
A giant thrombotic popliteal aneurysm with concomitant entrapment neuropathy and critical limb ischemia
}

\author{
Tuzak nöropati ve kritik ekstremite iskemisine neden olan \\ dev tromboze popliteal anevrizma
}

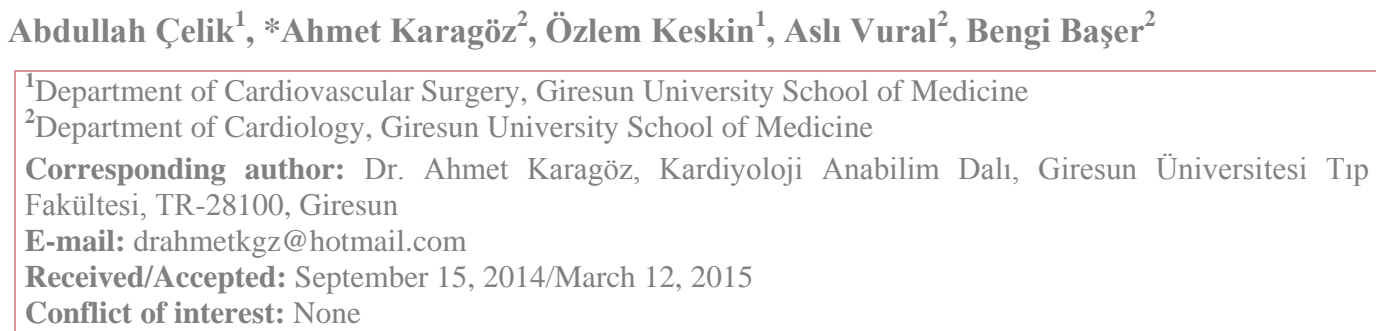

\section{SUMMARY}

Popliteal artery aneurysms are relatively common among all peripheral aneurysms. Nevertheless development of entrapment neuropathy or critical limb ischemia due to a popliteal aneurysm is extremely rare. Peripheral nerves such as tibial and common peroneal nerves are more frequently exposed to chronic compression due to settlement with a narrow anatomic volume and neighborhood with a joint. Herein we present a case of a thrombotic popliteal aneurysm causing entrapment neuropathy and critical limb ischemia.

Keywords: Popliteal artery aneurysm, entrapment neuropathy, limb ischemia

\section{ÖZET}

Popliteal arter anevrizmaları periferal arter anevrizmaları içinde nispeten yaygın olarak gözlenmektedir. Bununla birlikte popliteal anevrizmaya bağlı olarak tuzak nöropati veya kritik ekstremite iskemisi gözlenmesi oldukça nadiridir. Tibial ve common peroneal sinirler periferik sinirler arasında daha dar bir anatomik bölgede yerleşmiş olmaları ve eklem komşulukları nedeni ile kronik basıya daha sıkılıkla maruz kalırlar. Biz burada tuzak nöropatisi ve kritik ekstremite iskemisine neden olan bir tromboze popliteal anevrizma olgusunu sunuyoruz.

Anahtar sözcükler: Popliteal arter anevrizması, tuzak nöropati, ekstremite iskemisi.

\section{INTRODUCTION}

Popliteal artery aneurysms (paa) are the most common type of peripheral aneurysms because the protection of the popliteal region via surrounding muscle is weaker. They are frequently observed in men ${ }^{1}$. A paa may cause a variety of compressive and occlusive complications. Intermittent claudication as a result of thrombosis, acute limb ischemia and nerve compression resulting in entrapment neuropathies can be seen in the clinical course. One third of PAAs are asymptomatic when diagnosed. In symptomatic patients, rupture in $10 \%$ of the cases and nerve or vein pressure in 5\% to $10 \%$ of cases are present and the rest of the patients present with acute or chronic extremity ischemia findings ${ }^{2}$. Herein we present a case of a thrombotic popliteal aneurysm causing entrapment neuropathy and critical limb ischemia.

\section{CASE REPORT}

A 82 years old male patient presented with severe pain, paresthesias and numbness on the left leg. Anamnesis revealed pain which was caused by walking (claudication) and numbness for two months. His complaints had deepened in the last one week and make him apply to 
the hospital. Following his first visit in orthopedics clinic, he was consulted to neurology and cardiovascular surgery departments. In his evaluation in neurology department, neuropathy was detected in the region of tibial and common peroneal nevres in electromyography (EMG). But the main problem was thought to be the compression of the mass in the popliteal fossa and the patient was referred to cardiovascular surgery.

He did not define a history of trauma and any other chronic systemic disease. In physcical examination, a nonpulsatile mass in left popliteal fossa and dysfunction of left lower extremity were detected. Popliteal artery and distal pulses could be palpated scarcely. Ankle-brachial index (ABI) was found to be 0.3. The arterial Doppler ultrasound presented thrombosed popliteal artery aneurysm in the left popliteal level and also showed complete occlusion. Following this, the aortafemoral computed tomographic (CT) angiography detected thrombosed popliteal artery aneurysm $4.5 \times 5.5 \mathrm{~cm}$ in diameter in the popliteal fossa and postaneurysmatic distal vascular occlusion (Figure: 1, 2)

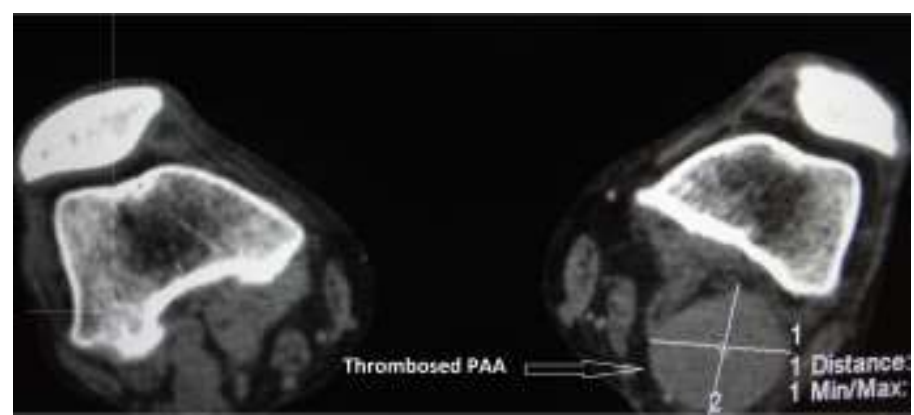

Figure 1: Preoperative computed tomographic view of popliteal aneurysm.

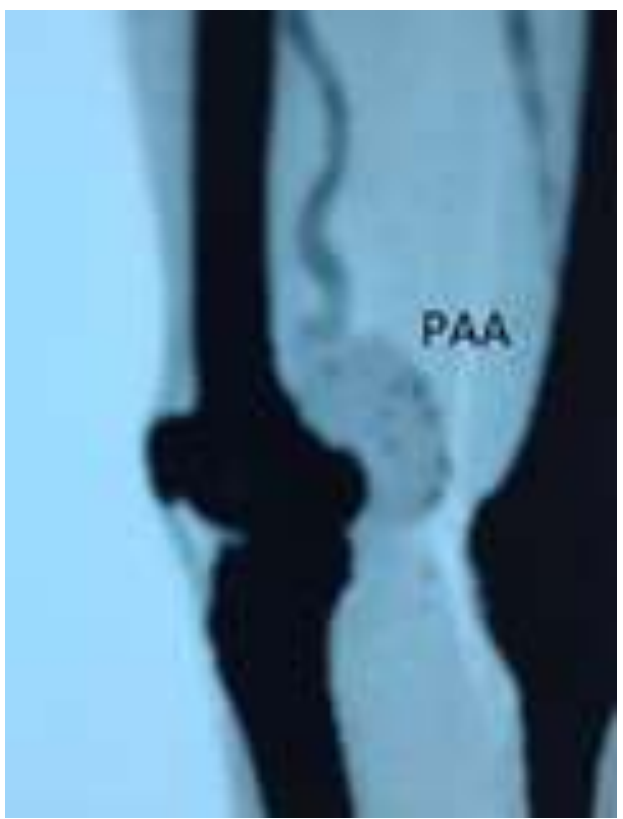

Figure 2: Appearance of postaneurysmatic vascular occlusion.

The patient was taken to operation room under emergency conditions and spinal anesthesia was performed. In operation, via posterior approach and performing incision to the output of hunter channel, superficial femoral artery was suspended. Then the popliteal artery was suspended with the incision made just above trifurcation.

In the exploration of aneurysmal segment between two incisions, popliteal vein, tibial and peroneal nerves were found to be under severe pressure and also extensive adhesions were detected (Figure 3). 


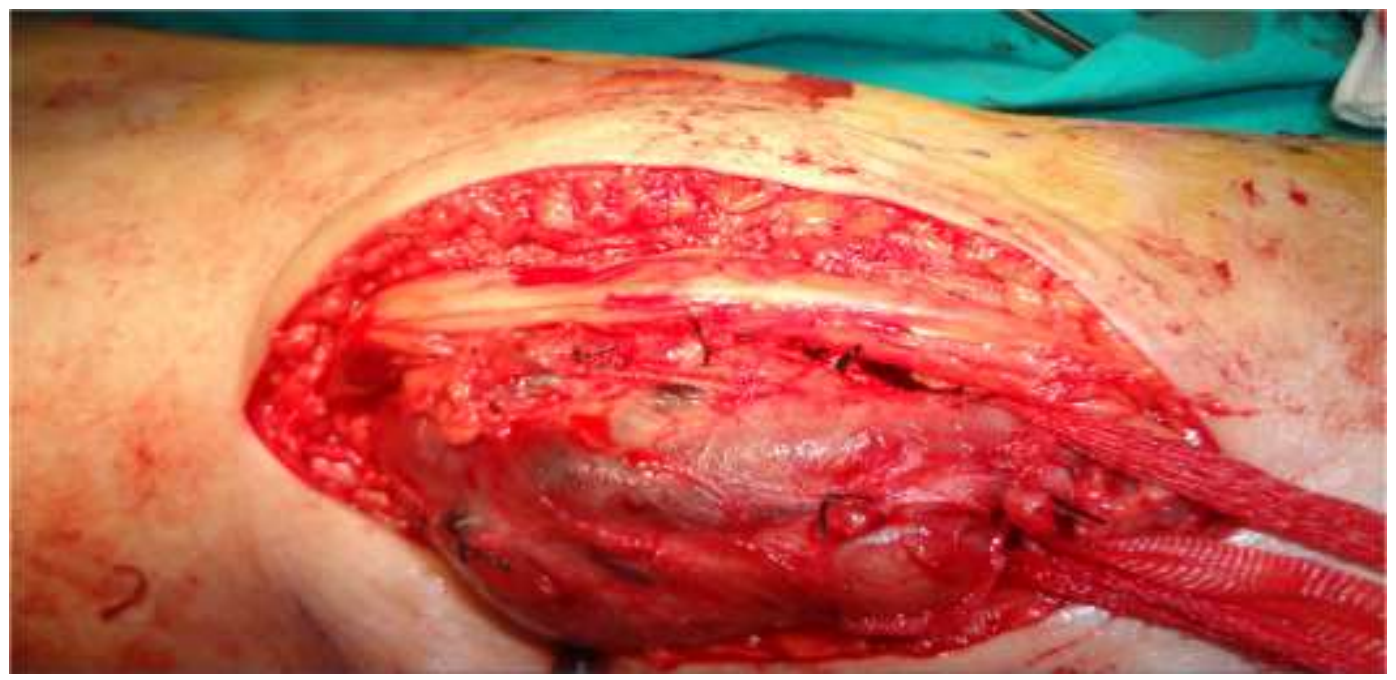

Figure 3: Intraoperative appearance before excision of the aneurysmal segment.

After liberalization of the poplitael vein, tibial and peroneal veins, aneurysmectomy was performed. On the ground that he had severe venous insufficiency and varicosity in one lower extremity and history of vascular surgery in the other, saphene vein graft could not be used and a $6 \mathrm{~mm}$ polytetrafluoroethylene tube graft inter- position was applied (Figure 4). After the operation, left lower extremity distal pulses were palpable $(A B I=1)$. In the postoperative period, the patient who had complete resolution of peripheral ischemia and neuropathy complaints, was discharged uneventfully.

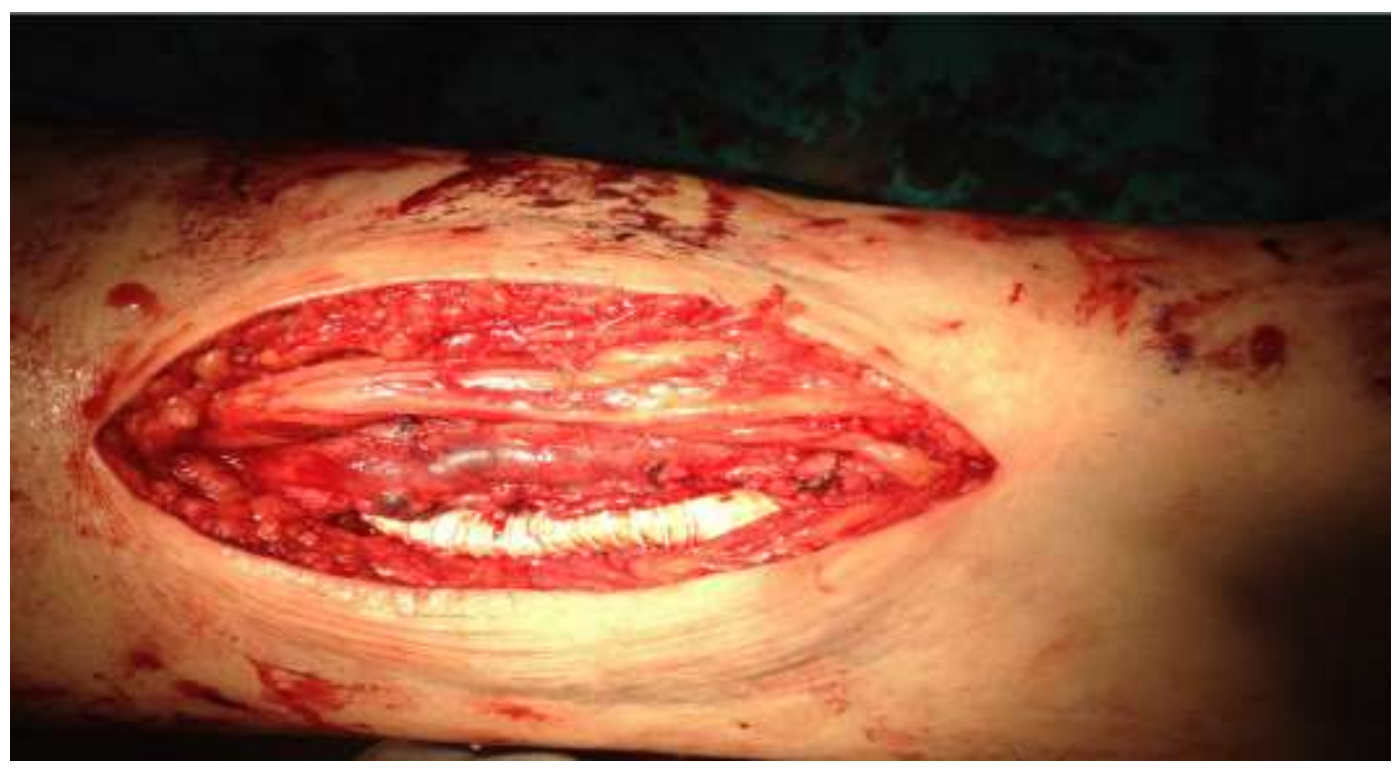

Figure 4: Appearance of polytetrafluoroethylene tube graft after excision of thrombus.

\section{DISCUSSION}

In patients with popliteal artery aneurysm, acute ischemic changes due to popliteal artery thrombosis and distal embolization, and extremity dysfunction caused by nerve and vein compression may develop. In the literature, mostly, compression due to arterial origin have been reported; these may be tortuous artery, persistent artery, and enlarged arteries due to anatomical variations, hemangioma and aneurysm ${ }^{3}$. Entrapment neuropathies occur due to mechanical compression of isolated peripheral nerves in specific areas along their anatomical course. In some cases, chronic nerve is injured by direct compression, and sometimes angulation or stretching forces affect the nerve mechanically. Entrapment neuropathies in the lower extremities are less often than the upper extremities. It is characterized by 
pain and loss of function in the area of the compressed nerve. Vascular lesions resulting in compression of the peripheral nerves and neuropathies are rarely reported ${ }^{4}$. Peripheral nerves such as tibial and common peroneal nerves are more frequently exposed to chronic compression due to settlement with a narrow anatomic volume and neighborhood with a joint. This type of nerve lesions which are seen as a result of repetitive compression are the most common cause of focal neuropathy. Compression of the tibial nerve in the popliteal region is rare, but the baker's cyst, popliteal aneurysm or a tumor may cause compression of the nerve. This neuropathy is characterized by weakness of the foot plantar flexors, inverter and intrinsic muscles. Sensory loss is in the sole of the feet and sometimes may be in the area of the sural nerve. Loss of Achilles reflex is usually present. PAAs can progress to loss of extremity and may be considered among the diseases with high morbidity in the absence of effective follow-up and treatment. Bajardi $\mathrm{G}$ et $\mathrm{al}^{5}$ recently reported a pulmonary artery aneurysm presenting with extrinsic popliteal vein occlusion and compartment syndrome. Compression of common peroneal and distal sciatic nerves by a popliteal artery aneurysm were also reported $^{6,7}$. Logigian EL et al $^{8}$ reported concomitance of peroneal and tibial nerve injury but this time due to hemorrhage instead of an aneurysm. The points that make our case worthy of reporting were existence of a large aneurysm causing limb ischemia in the lower extremity which was mentioned to be less often and compression of both tibial and peroneal nerves. Development of such a large peripheric aneurysm in the absence of known coronary or peripheric artery disease is another point that should be emphasized. Surgical approach is planned because of popliteal artery aneurysm width and presence of occlusive vascular disease. In our case, urgent surgical repair was performed via posterior approach because of acute occlusion causing severe limb ischemia and neuropathy secondary to compression. As a result, entrapment neuropathy and ischemic findings may be the first clinical manifestations of an enlarged popliteal aneurysm even in the absence of known peripheral and coronary artrey disease and we believe that popliteal aneurysm operation via posterior approach at an early stage is a lim bsaving technique with low mortality and morbidity.

\section{REFERENCES}

1. Aulivola B, Hamdan AD, Hile CN, Sheahan MG, Skillman JJ, Campbell DR. Popliteal artery aneurysms: A comparison of outcomes in elective versus emergent repair. J Vasc Surg 2004; 39: 1171-7.

2. Sarcina A, Bellosta R, Luzzani L, Agrifoglio G.Surgical treatment of popliteal artery aneurysm. A 20 year experience. J Cardiovasc Surg 1997; 38: 347-54.

3. Segal R, Machiraju U, Larkins M. Tortuous peripheral arteries: A cause of focal neuropathy. Case report. J Neurosurg 1992; 76: 7014.

4. Donovan A, Rosenberg ZS, Cavalcanti CF. MR Imaging of entrapment neuropathies of the

5. lower extremity. RadioGraphics 2010; 30: 1001-9.

6. Bajardi G, Pecoraro F, Vitale G, La Rosa G, Bellisi M, Bracale UM. A popliteal artery aneurysm presenting with $a b$ extrinseco popliteal vein occlusion and compartment syndrome: A case report. Ann Ital Chir 2012; 83: 441-4.

7. Ersozlu S, Ozulku M, Yildirim E, Tandogan R. Common peroneal nerve palsy from an untreated popliteal pseudoaneurysm after penetrating injury $\mathrm{J}$ Vasc Surg 2007; 45: 408-10.

8. Beaudry Y, Stewart JD, Errett L. Distal sciatic nerve compression by a popliteal artery aneurysm. Can J Neurol Sci 1989; 16: 352-3.

9. Logigian EL, Berger AR, Shahani BT. Injury to the tibial and peroneal nerves due to hemorrhage in the popliteal fossa. Two case reports. J Bone Joint Surg Am 1989; 71: 768-70. 